ENCYCLOPÉDIE Encyclopédie berbère

BERBERE

$34 \mid 2012$

34| Nemencha - Nybgenii

\title{
Nicibes / Nicives
}

Jehan Desanges

\section{OpenEdition}

Journals

Édition électronique

URL : https://journals.openedition.org/encyclopedieberbere/2739

DOI : 10.4000/encyclopedieberbere. 2739

ISSN : 2262-7197

\section{Éditeur}

Peeters Publishers

\section{Édition imprimée}

Date de publication : 5 octobre 2012

Pagination : 5552-5553

ISBN : 978-90-429-2718-6

ISSN : 1015-7344

\section{Référence électronique}

Jehan Desanges, « Nicibes / Nicives », Encyclopédie berbère [En ligne], 34 | 2012, document N55, mis en ligne le 15 décembre 2020, consulté le 17 février 2022. URL : http://journals.openedition.org/ encyclopedieberbere/2739; DOI : https://doi.org/10.4000/encyclopedieberbere.2739

Ce document a été généré automatiquement le 17 février 2022.

(c) Tous droits réservés 


\title{
Nicibes / Nicives
}

\author{
Jehan Desanges
}

1 Pline l'Ancien $(\mathrm{V}, 30)$ mentionne les Niciues parmi les principaux peuples (nationes) de

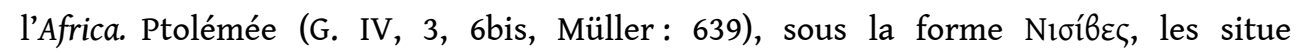
apparemment à l'est des Nattaboutes (cf. Nattabutes*), eux-mêmes placés au-dessous, c'est-à-dire au sud, des Misoulami (cf. Musulames*). On a donc l'impression d'un peuple implanté dans la Numidie proconsulaire, peut-être dans la région de Thubursicu Numidarum (Khamissa). Or ils sont attestés par deux inscriptions, sous Vespasien, à l'ouest sud-ouest des Nattabutes, à $3 \mathrm{~km}$ au nord-ouest de Tigisi (Aïn el-Bordj) (Lancel ; $\left.A E, 1957, \mathrm{n}^{\circ} 175\right)$ et à $1 \mathrm{~km}$ à l'ouest de Bir Fradj (Berthier; pour la situation, cf. AAA, f. $\left.17, n^{\circ} 186\right)$. Ces inscriptions nous apprennent qu'ils ont reçu en jouissance, en même temps qu'une autre tribu, les Suburbures*, des terrains appartenant aux Cirtéens. À basse époque, les Niciues christianisés (mais soumis auparavant dans leur culte à des influences puniques notables, peut-être par l'intermédiaire de Cirta, cf. N52. N'gaous*) étaient fixés autour d'une agglomération qui portait leur nom à l'ablatif-locatif: Niciuibus, actuellement N'gaous (AAA, f. 26, $\mathrm{n}^{\circ} 161$ ), au nord des monts de Batna, dans la vallée de l'oued Barika qui mène au chott el-Hodna. Des évêques Nicibensis ou Niciuensis sont attestés en 411, 484 (Ni[ci]bensis) et 581/582 (Mesnage : 343), le dernier à $\mathrm{H}^{\mathrm{r}} \mathrm{Akhrib}$, à $14 \mathrm{~km}$ au N. N.-E. de N'gaous, très vraisemblablement sur son diocèse. Du fait qu'un prêtre nommé Floridus, attesté en 543 à $\mathrm{H}^{\mathrm{r}}$ Akhrib, l'est également à Aïn Guigba (AAA, f. $26, n^{\circ} 78$ ), à une quinzaine de km plus au nord, faut-il conclure, avec Leschi (p. 315) que le territoire des Niciues, ou plutôt de leur ville, s'étendait assez loin vers le nord ? Bien qu'il y ait eu des évêchés attribués à des tribus (episcopus Cedamusensis, Mazacensis, Numidensis), l'étendue du diocèse pouvait ne pas correspondre exactement à l'implantation de la communauté tribale.

2 Il est clair, en tout cas, que, comme c'est le cas pour les Sabarbares/Suburbures* ou les Musulames*, les lieux où est attestée l'implantation des Niciues varient selon l'époque. Certes, on peut l'expliquer par des phénomènes de fractionnement ou de nomadisme saisonnier. Mais un refoulement des tribus les plus turbulentes par l'autorité romaine à partir du nord-est de l'Afrique Mineure vers la Maurétanie est une hypothèse que l'on ne peut écarter. Nous savons que sous les Sévères des populi (communautés reconnues 
et recensées par le fisc romain), qualifiés de noui furent constitués en Maurétanie intérieure à partir d'éléments importés de l'Africa (Desanges : 85-90).

$3 \rightarrow$ Voir aussi N52 et N53 « N'gaous "

\section{BIBLIOGRAPHIE}

BERTHIER A., 1968 - « Nicibes et Suburbures. Nomades ou sédentaires ? », Bull. arch. alg., III, p. 293-300.

DESANGES J., 2001 - « De la Marmarique à la Maurétanie. Nouvelles données en matière de mouvements de population », Antiquités africaines, 37, p. 81-91.

LANCEL S., 1955 - « Suburbures et Nicibes : une inscription de Tigisis », Libyca arch.-épigr., III, p. 289-298.

LESCHI L., 1957 - « Reliquaires chrétiens du VI ${ }^{\mathrm{e}}$ siècle en Numidie », Études d'épigraphie, d'archéologie et d'histoire africaines, Paris, p. 313-317 = CRAI, 1934, p 236-245.

MESNAGE J., 1912 - L'Afrique chrétienne, Paris.

INDEX

Mots-clés : Antiquité, Numidie, Tribu 